\title{
Erratum to: Modernizing State Support of Nonprofit Service Provision: The Case of Kyrgyzstan
}

\author{
Yulia Shapovalova ${ }^{1,2}$
}

Published online: 6 October 2016

(c) International Society for Third-Sector Research and The Johns Hopkins University 2016

\section{Erratum to: Voluntas (2015) 26:2379-2394 DOI 10.1007/s11266-015-9649-0}

An affiliation should be added to the author of this paper: National Research University Higher School of Economics, Moscow, Russian Federation.

The online version of the original article can be found under doi:10.1007/s11266-015-9649-0.

$\triangle$ Yulia Shapovalova yshapovalova107@gmail.com

1 Queen Mary University, London, UK

2 National Research University Higher School of Economics, Moscow, Russian Federation 